\title{
New Generation Antibiotics/Antibacterials: Deadly Arsenal for Disposal of Antibiotic Resistant Bacteria
}

\author{
Monica Sharma*1,2, Shashank Singh ${ }^{2}$ and Sidharth Sharma ${ }^{2}$
}

${ }^{1}$ Department of Biotechnology, School of Biosciences and Biotechnology, Babasaheb Bhimrao Ambedkar University, Vidya Vihar, Raebareli Road, Lucknow, Uttar Pradesh, India

${ }^{2}$ Department of Biotechnology, Delhi Technological University, Main Bawana Road, Shahbad Daulatpur, Delhi, India

\begin{abstract}
Inappropriate prescribing, lack of compliance in taking medicines and wise spread uncontrolled use of drugs led to emergence of multidrug resistance in clinically important infectious agents. Over 480000 new cases of multidrug-resistant tuberculosis (MDR-TB) were reported by WHO in the year 2013 in hundred countries world wide. Therefore, there is an urgent need for new generation antibacterial which can effectively and precisely act on drug resistant bacteria. Different strategies of development of resistance in bacteria involve the changes at molecular level like mutations, over expression of enzymes and efflux. So, the strategies of antibiotics development can include methods which can counteract at molecular level like antisense antibacterial and inhibition of quorum sensing. Bacterial gene rpoD found in Staphylococcus species is highly conserved and became basis in creation of antisense antibacterial against it. Lipid II class of antibiotics including teixobactin and antimicrobial peptides (AMPs), i.e. produced synthetically, have also shown promising results against the resistant bacterial strains. The present review summarizes the current scenario on research and development of new age antibiotics and techniques to tackle drug resistant bacterial infection.
\end{abstract}

Keywords: Teixobactin; Anti-microbial peptides; Ctriporin; BetaLactum

\section{Introduction}

The last century saw the emergence of antibiotics as wonder drugs which not only saved million lives but also revolutionsed the arena of advanced medical sciences. These drugs have not only reduced the mortality during routine surgery and childbirth to negligible, and but also reduced the stigma associated with HIV which was once considered as deadly disease. In recent times due to exposure to various xenobiotics/drugs, bacteria are evolving so rapidly that they have developed resistant against antibiotics/antibacterial and hence pose serious threat to health [1]. Resistance development limits the use of antibacterials and this increases the demand of introduction of new compounds $[2,3]$. When early resistance to penicillin was observed, second generation antibiotics, methicillin, cephalothin and imipenem were already developed [4]. In 1961, a methicillin resistant strain of $S$. aureus (MRSA) was observed [5] and at present worldwide, an estimated 2 billion peoples carry some form of $S$. aureus and of these up to 53 million (2.7\% of carriers) are thought to carry MRSA [6]. Over the years it has become clear that bacteria can develop resistance to almost any antibiotic. Except a few antibiotics, for instance erythromycin and vancomycin, resistance was developed against majority of antibacterials only a few years after their introduction into clinical use $[7,8]$.

The mechanism of development of resistance in bacteria is mainly consisting of three strategies- (i) overexpression of enzymes that can modify the antibiotic drug rendering the antibiotic inactive; (ii) mutation of the bacterial target site that allows the target site to maintain its functional role yet abrogates binding of drug to the target or transverse of the antibiotic across the bacterial cell wall; (iii) export of antibiotic drugs to the extracellular media via multidrug-resistant (MDR) efflux pumps or loss of porin channels resulting in lower permeability of antibiotics (Figure 1) [9]. For example-drugs such as $\beta$-lactams, are inactivated via the over expression of $\beta$-lactamases, which hydrolyze the antibiotics [10], antibiotics such as linezolidare and the streptogramin class rendered ineffective via the modification of $23 \mathrm{~S}$ ribosomal RNA [11] and efflux pump proteins such as AcrB in E. coli [12] export antibiotics such as ciprofloxacin and tetracycline out of bacterial cells.

The aim of this review is to explore the current status of research and development of antibacterial compounds and techniques to tackle the bacterial infection.

\section{Teixobactin}

Teixobactin is the first of its kind of antibiotic that provides a

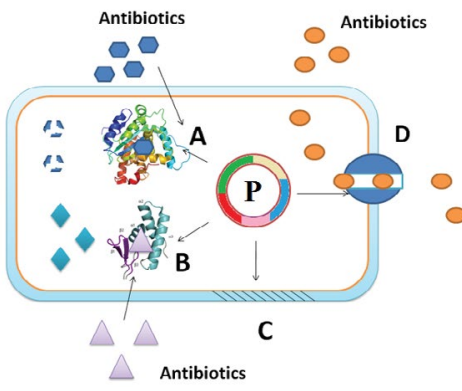

$A=$ Antibiotic degrading enzyme $B=$ Antibiotics modifying enzym $\mathrm{C}=$ Cell wall modifying proteins D= Efflux pump

$\mathrm{P}=$ Plasmid containing antibiotic resistantgenes

Figure 1: General mechanism of developing antibiotic resistance in bacteria.

*Corresponding authors: Monica Sharma, Department of Biotechnology, Delhi Technological University, Main Bawana Road, Shahbad Daulatpur, Delhi, India, Tel: +91-9717386785; E-mail: monashimla@gmail.com

Received September 26, 2015; Accepted October 20, 2015; Published October 27,2015

Citation: Sharma M, Singh S, Sharma S (2015) New Generation Antibiotics/ Antibacterials: Deadly Arsenal for Disposal of Antibiotic Resistant Bacteria. J Microb Biochem Technol 7: 374-379. doi:10.4172/1948-5948.1000241

Copyright: @ 2015 Sharma M, et al. This is an open-access article distributed under the terms of the Creative Commons Attribution License, which permits unrestricted use, distribution, and reproduction in any medium, provided the original author and source are credited. 


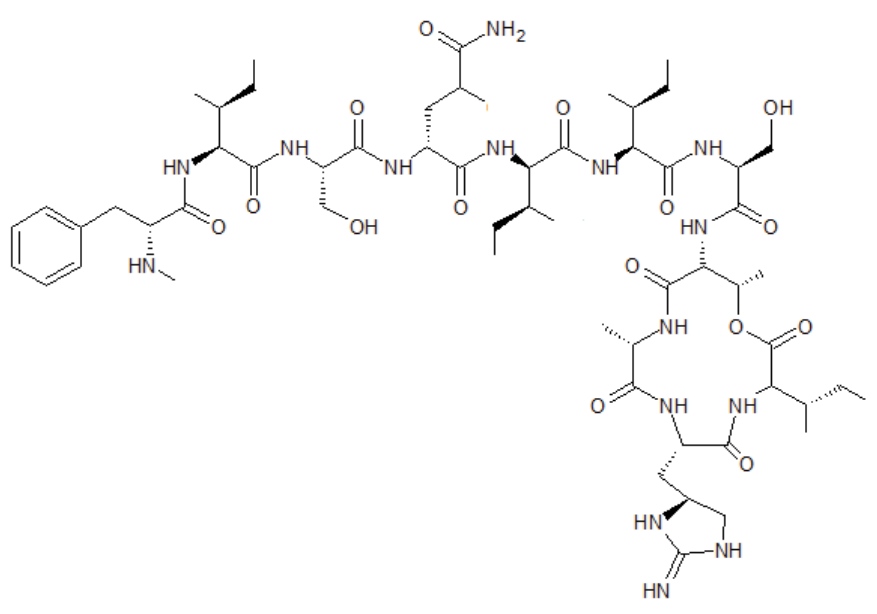

Figure 2: Structure of Teixobactin.

maiden entry to a more promising lipid II class of antibiotics (Figure 2). It is different from other known antibiotics like glycopeptides, lantibiotics and defensins in both its mode of action and structure [13-15]. Teixobactin is light of new hope in this era of incessantly growing antibiotics resistance; it is found out to be effective against a number of drug- resistant pathogenic microbes in some animal models of infection. Attack of teixobactin involves its binding to the wall of teichoic acid precursor that leads to the efficient lysis of cells and also the killing of cells by action of liberated autolysins [16]. Action of teixobactin is similar to the one other naturally occurring compound with a competent killing ability, 'acyldepsipeptide'. It converts the ClpP protease into a non-specific hydrolase which finally digests the cell [17]. Multiple targets are involved in the action of teixobactin out of which none of them is a protein.

Gram positive bacteria possess easily accessible lipid II which are poly prenyl precursors coupled to cell envelop and they represent a deadly weakness for antibiotic attack [18]. Among eubacteria pyrophosphate-sugar moiety of teixobactin target molecules is highly conserved. Gram-negative bacterium is one of those producers and its external membrane protects the bacterium from the re-entry of the compound. Henceforth, it is suggested by the study that the producer does not hires an alternative pathway for the synthesis of cell wall that would protect it from teixobactin. Therefore other bacteria couldn't borrow it. Horizontal transmission of a confrontation mechanism could sooner or later arise from some soil bacterium. The highly conserved teixobactin binding motif can take the form of an antibiotic modifying enzyme. Beta-lactams or aminoglycosides are those common antibiotics that codes for enzymes which attacks recurrently and they are unidentified for the vancomycin.

Newly discovered teixobactin is even less common than vancomycin. After its introduction into the clinic, it took years for vancomycin resistance to appear [19]. The lipid II modification pathway leading to vancomycin resistance possibly originated in the producer of vancomycin, Amycolatopsis orientalis [20]. Perhaps this could take even longer for resistance to better-protected teixobactin to emerge. The properties of teixobactin suggest that it evolved to minimize resistance development by target microorganisms. It is expected that additional natural compounds with similarly low susceptibility to resistance are present in nature and are waiting to be discovered [21]. However, teixobactin is not active against bacteria with an outer membrane like gram negative pathogens, particularly carbapenem resistant enterobacteriaceae, or those with New Delhi metallo-betalactamase 1 [22].

\section{Antisense Antibacterial}

Antisense antibacterials are short (about 10 to 20 bases), synthetic DNA analogs that constrains the essential genes expression at mRNA level in a sequence-specific manner [23]. Thereafter, antisense inhibition leads to bacteriocidal or bacteriostatic effect or restoration of bacterial susceptibility, which relies on the role of targeted gene. Synthetic antisense oligomers, particularly phosphorodiamidate morpholino (PMO) [24] and peptide nucleic acid (PNA) [25], possess favorable properties in light of antisense antibacterial application. It also includes enhanced biological stability, targeting specificity, binding affinity and access to an array of chemical modifications. Meanwhile, instead of simple mixture, cell penetrating peptides (CPP) can be covalently attached or conjugated at the end of PNA or PMO chain to upgrade cellular uptake of antisense oligodeoxynucelotides (ASODNs) without affecting Watson-Crick base paring between antisense oligomers and targeted RNAs [26]. Synthetic peptide- PNA or peptide-PMO conjugates targeting growth-essential genes shown to inhibit bacterial progression in pure culture and in infected tissue culture too. Therefore, a range of functional genes have been identified as potential targets [27]. However, only a few initial reports provided preliminary proof-of-principle support on antisense targeting of $S$. aureus genes for growth inhibitory effect (i.e., peptide-PNA targeting fabI [28] and phoB, fmhB, gyrA, plus hmrB.

Bacterial DNA-dependent RNA polymerase (RNAP) plays a vital role in transcription regulation and gene expression. Function of which requires coordination of a core enzyme (comprising five subunits $\alpha_{2}, \beta, \beta^{\prime}$ and $\Omega$ ) and an independent $\sigma$ subunit that is reversibly employed by core enzyme [29]. The RNAP core enzyme is accountable for transcription elongation whereas different $\sigma$ s bind to different promoters to initiate transcription of genes of varied function. This irreversible inhibition of RNAP thereby causes cell death. It has engrossed much exploration for developing specific RNAP inhibitors (e.g., the rifamycins with fundamental clinical significance). The most developed $\sigma 70$ family of $\sigma s$, especially the primary $\sigma 70$, is essential for initiating transcription of multiple genes in exponential growth cells [30], which to our knowledge has not previously been demonstrated for antisense target validation in $S$. aureus. The primary 670 s are found to be unique in structure, function as well as homology. The core regions of bacterial and eukaryotic RNAPs share structural and functional similarities, but the sequences of encoding genes are only partially homologous. Specifically, bacterial gene rpoD (encoding the primary $\sigma 70$ of RNAP) shares the least homology in sequence with eukaryotic rpoD. Hence, in contrast to more conserved molecules, sequence-based drugs targeting $\mathrm{rpoD}$ products, including mRNAs, are less likely to cross react with host molecules. Most importantly, bacterial gene rpoD is highly conserved in identity and homologous in sequence among different pathogenic Staphylococcus species [31]. Such features are of distinctive advantages for developing narrow-spectra of anti-MRSA antisense agents.

\section{Antimicrobial Peptides (AMPs)}

In year 1939 Dubas discovered antimicrobial peptides [32]. Both Dubos and Hotchkiss identified an AMP in the following year which was named as gramicidin [33]. It was found to be very effective for topical treatment of wounds and ulcers [34]. AMPs, the major components of 
innate immune system play a vital role in the host defense mechanism against environmental microorganisms. They are well versed in nature, existing in organisms from insects to plants and from microorganisms to mammals. AMPs have broad spectra of activity against infectious agents that includes Gram-negative and Gram-positive bacteria, fungi, viruses, and parasites too and rapid action. Cationic peptides are not affected by many antibiotic resistance mechanisms that now bound the use of other antibiotics $[35,36]$. Furthermore, in some of the cases, certain AMPs have been reported to kill antibiotic resistant bacteria e.g., both nisin (an AMP) and vancomycin (an antibiotic) kill bacteria by blocking their cell wall synthesis. However, MRSA (methicillin resistant Staphylococcus aureus) strain was reported to be resistant to vancomycin, while it was still sensitive to nisin [37].

In total, more than 5,000 AMPs have been discovered or synthesized up to date [38]. Natural AMPs can be found in both prokaryotes (e.g., bacteria) and eukaryotes (e.g., protozoan, fungi, plants, insects, and animals) [39-42] whereas in animals, AMPs are mostly found in the tissues and organs that are exposed to airborne pathogens. They are believed to be the first line of the innate immune defense $[43,44]$ against viruses, bacteria, as well as fungi [40].

Most AMPs reported till date can be characterized on the basis of their secondary structures and classified into four types: $\beta$-sheet, $\alpha$-helix, extended, and loop. Among these structural elements, $\alpha$-helix and $\beta$-sheet structures are more common [45] and $\alpha$-helical peptides are the most extensively studied AMPs (Table 1). In $\alpha$-helix conformation the distance between two adjacent amino acids is around $0.15 \mathrm{~nm}$ and the angle between them with regard to the center is around 100 degree from the top view. The best known examples of $\alpha$-helical AMPs are magainin, protegrin, cyclic indolicin and coiled indolicin [46]. $\beta$-sheet peptides are composed of at least two $\beta$-strands with disulfide bonds between these strands [47]

Researchers have identified, cloned and characterized a novel antimicrobial peptide from the venom of the scorpion Chaerilus tricostatus and named it as ctriporin [58]. The mature peptide of ctriporin was composed of 19 amino acid residues and possessed amidated C terminus. At low concentrations Ctriporin showed potent growth-inhibitory activity against standard Candida albicans and Gram-positive bacteria. Moreover, the in vitro treatment of clinically isolated pathogenic strains exhibited that ctriporin can also restrain antibiotic-resistant pathogens, including MRSA, methicillin-resistant coagulase-negative Staphylococcus (MRCNS), and penicillin- resistant Staphylococcus epidermidis (PRSE) strains. Ctriporin antimicrobial activity was explored in in vivo ointment application in topical treatment of mouse skin infection model. Finally, a standard Grampositive bacterium, $S$. aureus, as a model bacterial strain is chosen to further explore the antimicrobial mechanism of ctriporin. All research about Ctriporin indicate it as an effective promising antimicrobial agent which act via the bactericidal mechanism of the rapid cell lysis [58].

\begin{tabular}{|c|c|c|}
\hline S.No & Classes of AMPs & Examples \\
\hline 1. & Antiviral Peptides [48,49] & $\begin{array}{c}\text { Heparan Sulfate (gllycosaminoglycan) } \\
\text { Lactoferrin (cationic peptides) }\end{array}$ \\
\hline 2. & $\begin{array}{c}\text { Antibacterial Peptides } \\
{[37,50-52]}\end{array}$ & $\begin{array}{c}\text { Buforin } \\
\text { Drosocin, Pyrrhocoricin \& Apidaecin } \\
\text { Nisin }\end{array}$ \\
\hline 3. & $\begin{array}{c}\text { Antifungal Peptides } \\
{[53-55]}\end{array}$ & $\begin{array}{c}\alpha \text { helical(D-V 13K and P18) } \\
\text { sheet (Defensins) } \\
\text { Indolicin }\end{array}$ \\
\hline 4. & Antiparasitic Peptides [56,57] & $\begin{array}{c}\text { Magainin } \\
\text { Cahelicidin }\end{array}$ \\
\hline
\end{tabular}

Table 1: Classifications of AMPs.

\section{Inhibition of Quorum Sensing}

Quorum sensing is a communication services or a system of communication between bacterial cells, whereby bacterial cells secrete and receipt signaling molecules from the local environment. A sufficient amount of inducer molecules is required to trigger the expression or suppression of specific genes responsible for bacterial activities like virulence gene expression, biofilm formation and resistance against antibiotic treatment [9]. Almost all quorum-sensing processes use micro molecules, known as autoinducers (AIs). Most frequently studied autoinducers belong to one of the following classes: acylated homoserine lactones (AHLs) used by Gram-negative bacteria (also sometimes called autoinducer-1 [AI-1]); peptide signals used by Gram-positive bacteria; and autoinducer-2 (AI-2) used by both Gramnegative and Gram-positive bacteria [59].

Inhibition of Quorum Sensing is one of the latest therapeutics development technologies that aim at targeting functions that are important for the infection. This technique has various potential benefits that include increase in range of bacterial targets, exertion of less selective stress and preservation of the host endogenous microbiome, which could ultimately result into the decreases resistance [60]. Several measures that were taken to inhibit regulation of virulence factors have engrossed on their interference with QS. Various efforts have been taken to discover the compounds along with inhibitory QS systems due to the vital role of QS in modulation and regulation of hundreds of virulence factors in bacteria. These compounds shall inhibit the synchronized expressions of virulence determinants without prying with bacterial growth because they could stay along with the base of an anti-pathogenic strategy and this would ultimately generate less resistance [61].Some bacteria species can produce enzymes called lactonases that can target and inactivate AHLs. Researchers have developed novel molecules which block the signaling receptors of bacteria, $\mathrm{mBTL}$ is a compound that has been shown to inhibit quorum sensing [62]. Furthermore, several research groups are analyzing and developing some compounds of natural origin (such as caffeine) as potential quorum sensing inhibitors [63].

\section{Broadening the Spectrum of Beta-Lactam Antibiotics}

The resistance of MRSA strain to all Beta-lactam class antibiotics limits treatment recourse for serious ailments caused by this organism. Researchers discover new agents that restore the activity of beta-lactams against MRSA, an approach that has led to the discovery of two classes of natural product antibiotics, a cyclic depsipeptide (krisynomycin) and a lipoglycopeptide (actinocarbasin) [64], which potentiate the activity of imipenem against MRSA strain COL. Researchers reported that these imipenem synergists are inhibitors of the bacterial type I signal peptidase SpsB, a serine protease that is required for the secretion of proteins that are exported through the Sec and Tat systems [65]. A synthetic derivative of actinocarbasin, M131, synergized with imipenem was prepared and exhibited both in vitro and in vivo potent efficacy. The in vitro activity of M131 extends to clinical isolates of MRSA but not to a methicillin-sensitive strain (Figure 3).

Synergy is restricted to beta-lactam antibiotics and is not observed with other antibiotic classes. The current propose is that the SpsB inhibitors synergize with beta-lactams by preventing the signal peptidase-mediated secretion of proteins required for beta-lactam resistance. Combinations of SpsB inhibitors and beta-lactams may expand the utility of these widely prescribed antibiotics to treat MRSA 


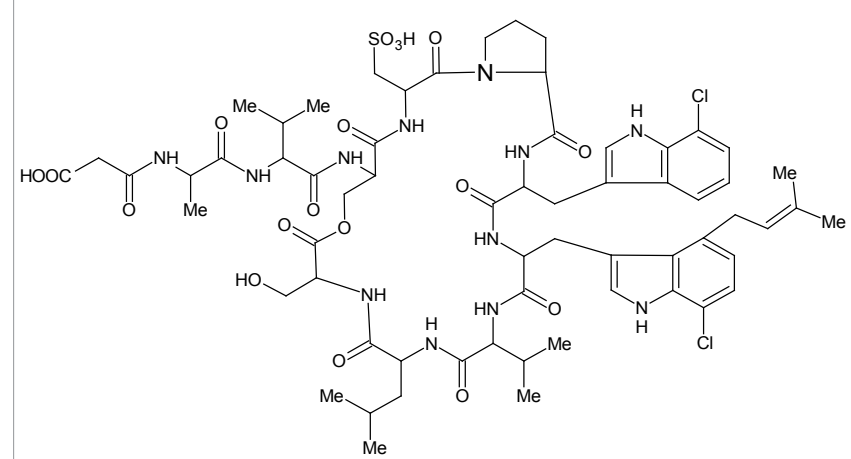

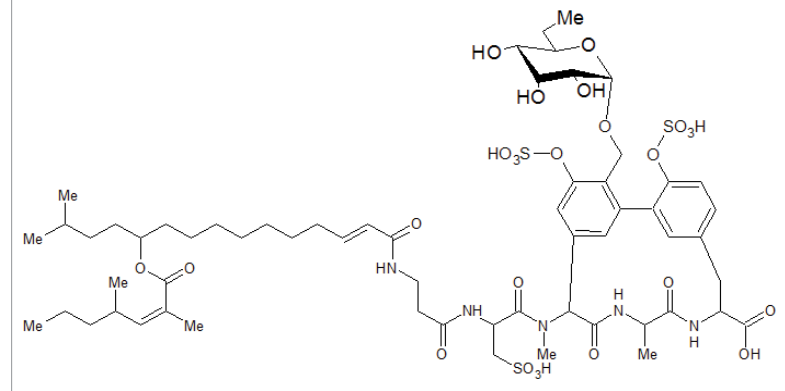<smiles>CCCc1ccc(-c2ccc(C(=O)NCCC(=O)N[C@@H](CCCCN)C(=O)N(C)C(C(=O)NCC(=O)CC(Cc3ccc(O)c(-c4cc(CC(=O)NCC)ccc4O)c3)C(=O)O)c3ccc(O)cc3)cc2)cc1</smiles>

Figure 3: $\beta$ - Lactam synergists. [A. Krisynomycin, B. Actinocarbasin and C. M131 synthetic derivative of actinocarbasin].

infections, analogous to beta-lactamase inhibitors which restored the utility of this antibiotic class for the treatment of resistant Gramnegative infections [64].

\section{Nano Metals as Antibacterial Agents}

Metals posess good thermal, electrical conductivity and chemical reactivity oweing to their large crystallographic suface area to volume ratio, hence can be potentially very toxic to the microbes. Due to their antimicrobial activity humans are using some metals since ages as antimicrobial agents in agriculture and medical uses e.g., silver has potential antimicrobial activity at unusual low concentrations [66]. Recently developed approaches in the domains of nanotechnology, especially the capability to produce metal oxide nanomaterials of definite size and shape, are liable to lead the development of new antibacterial agents [67]. Nanoparticles have received great attention due to their unique physical, chemical, and effective biological properties in various fields, including medicine. Considering these unique properties, nanosized organic and inorganic particles are being generated for ultimate use in medical practices, such as metal oxides of zinc, copper, and iron in biomedical research $[68,69]$.

Silver nanoparticles manifested biocide effect by anchoring and penetrating the bacterial cell wall and interact with sulfur- and phosphorus-containing biomolecules like DNA and silver ions strongly interacts with thiol groups of vital enzymes and inactivates them [70,71]. Silver exhibited more pronounced action against gram negative organisms than gram-positive bacteria and can inhibit growth of approximately 650 diesease causing agents. Silver nanoparticle based biocide showed that its antimicrobial effect is independent of acquisition of resistance against antibiotics [72]. Necessary metals such as copper also show similar properties but above some threshold levels $[73,74]$. The mode of action of the biocide activity is based on specific properties of metals and it can be activated by the metal reduction potential and the metal donor atom selectivity and/or speciation [66]. In addition, nanoparticles with smaller particle size have been reported to show good antimicrobial activity [75]. Antimicrobial activity of nanoparticles has largely been studied with human pathogenic bacteria such as Escherichia coli [76] and Staphylococcus aureus [77]. Moreover, these microbes seem to be highly sensitive to $\mathrm{ZnO}$ and $\mathrm{CuO}$ nanoparticles $[75,78]$. The cell can directly incorporate nanoparticles via endocytotic mechanisms and afterwards the cellular uptake of ions increases as ionic species are subsequently released within the cells by nanoparticle dissolution, a process often referred as "the Trojan horse mechanism". This high intracellular concentration gained after nanoparticle dissolution within the cell likely results in massive oxidative stress [79-81]. Recently bioactive glass BAG-S53P4 was reported to have anti-biofilm forming activity against MDR bacterial strains $[82,83]$.

\section{Conclusion}

According to an estimate the number of deaths caused by bacterial infection is highest in the world. There is an urgent need of novel antimicrobial drugs to fight against infection because bacteria are evolving and developing with a greater pace. We are surrounded by endless possibilities to fight against bacterial infection but only some of them are explored yet. Out of all existent antimicrobial drugs only a few have been taken to the clinical trials only a very few reached to the market for public use.

Teixobactin is a very effective drug against many pathogenic microorganisms which are resistant to the drugs currently in market. But it has some limitations for gram -ve bacteria. Anti-microbial peptides (AMPs) being a module of immune system though, can be synthesized for use as an antibiotics, which are very effective especially in topical treatment of ulcer etc. Cloned AMP ctriporin is a good example which a very effective role in inhibiting MRSA, MRCNS and PRSE. Molecular methods have also been employed for bacterial infection treatment involving antisense antibacterial and quorum sensing inhibitions which can easily overcome the resistance developed by micro-organisms and are very specific to its target. This can be a very sincere step in developing new antimicrobials.

\section{References}

1. Arias CA, Murray BE (2009) Antibiotic-resistant bugs in the 21st century--a clinical super-challenge. N Engl J Med 360: 439-443.

2. Spellberg B, Shlaes D (2014) Prioritized current unmet needs for antibacterial therapies. Clin Pharmacol Ther 96: 151-153.

3. Bush K, Courvalin P, Dantas G, Davies J, Eisenstein B, et al. (2011) Tackling antibiotic resistance. Nat Rev Microbiol 9: 894-896.

4. von Nussbaum F, Brands M, Hinzen B, Weigand S, Häbich D (2006) Antibacterial natural products in medicinal chemistry--exodus or revival? Angew Chem Int Ed Engl 45: 5072-5129.

5. Jevons MP (1961) ‘Celbenin'-resistant Staphylococci. Br Med J 1: 124-125.

6. Singh SK, Anwar S, Sharma HK, Chaudhary U, Verma SK (2014) FemAgene in Indian isolates of methicillin resistant Staphylococcus aureus, isolation and amplification through real time PCR. Euro J Exp Bio 4: 90-94. 
7. Shlaes DM, Marino J, Jacobs MR (1984) Infection caused by vancomycinresistant Streptococcus sanguis II. Antimicrob Agents Chemother 25: 527-528.

8. Uttley $\mathrm{AH}$, Collins $\mathrm{CH}$, Naidoo J, George RC (1988) Vancomycin-resistant enterococci. Lancet 1: 57-58.

9. Sintim HO, Smith JA, Wang J, Nakayama S, Yan L (2010) Paradigm shift in discovering next-generation anti-infective agents: targeting quorum sensing, c-di-GMP signaling and biofilm formation in bacteria with small molecules. Future Med Chem 2: 1005-1035.

10. Sanders CC, Sanders WE Jr (1979) Emergence of resistance to cefamandole: possible role of cefoxitin-inducible beta-lactamases. Antimicrob Agents Chemother 15: 792-797.

11. Gonzales RD, Schreckenberger PC, Graham MB, Kelkar S, DenBesten K et al. (2001) Infections due to vancomycin-resistant Enterococcus faecium resistant to linezolid. Lancet 357: 1179.

12. Sulavik MC, Houseweart C, Cramer C, Jiwani N, Murgolo N, et al. (2001) Antibiotic susceptibility profiles of Escherichia coli strains lacking multidrug efflux pump genes. Antimicrob Agents Chemother 45:1126-1136.

13. Wiedemann I, Breukink E, van Kraaij C, Kuipers OP, Bierbaum G, et al. (2001) Specific binding of nisin to the peptidoglycan precursor lipid II combines pore formation and inhibition of cell wall biosynthesis for potent antibiotic activity. J Biol Chem 276: 1772-1779.

14. Hasper HE, Kramer NE, Smith JL, Hillman JD, Zachariah C, et al. (2006) An alternative bactericidal mechanism of action for lantibiotic peptides that target lipid II. Science 313: 1636-1637.

15. Schneider T, Kruse T, Wimmer R, Wiedemann I, Sass V, et al. (2010) Plectasin a fungal defensin, targets the bacterial cell wall precursor Lipid II. Science 328 : 1168-1172.

16. Ling LL, Schneider T, Peoples AJ, Spoering AL, Engels I, et al. (2015) Erratum: A novel antibiotic kills pathogens without detectable resistance. Nature 520: 388.

17. Conlon BP, Nakayasu ES, Fleck LE, LaFleur MD, Isabella VM, et al. (2013) Activated ClpP kills persisters and eradicates a chronic biofilm infection. Nature 503: 365-370.

18. Schneider T, Sahl HG (2010) An oldie but a goodie - cell wall biosynthesis as antibiotic target pathway. Int J Med Microbiol 300: 161-169.

19. Leclercq R, Derlot E, Duval J, Courvalin P (1988) Plasmid-mediated resistance to vancomycin and teicoplanin in Enterococcus faecium. N Engl J Med 319 : $157-161$

20. Marshall CG, Broadhead G, Leskiw BK, Wright GD (1997) D-Ala-D-Ala ligases from glycopeptide antibiotic-producing organisms is highly homologous to the enterococcal vancomycin-resistance ligases VanA and VanB. Proc Natl Acad Sci USA 94: 6480-6483.

21. Ling LL, Schneider T, Peoples AJ, Spoering AL, Engels I, et al. (2015) A new antibiotic kills pathogens without detectable resistance. Nature 517: 455- 459.

22. Stone J (2015) Teixobactin and ichip promise hope against antibiotic resistance. Forbes.

23. Rasmussen LC, Sperling-Petersen HU, Mortensen KK (2007) Hitting bacteria at the heart of the central dogma: sequence-specific inhibition. Microb Cell Fact 6: 24

24. Geller BL (2005) Antibacterial antisense. Curr Opin Mol Ther 7: 109-113.

25. Hatamoto M, Ohashi A, Imachi H (2010) Peptide nucleic acids (PNAs) antisense effect to bacterial growth and their application potentiality in biotechnology. Appl Microbiol Biotechnol 86: 397-402.

26. Good L, Awasthi SK, Dryselius R, Larsson O, Nielsen PE (2001) Bactericidal antisense effects of peptide-PNA conjugates. Nat Biotechnol 19: 360-364.

27. Bai H, Zhou Y, Hou Z, Xue X, Meng J, et al. (2011) Targeting bacterial RNA polymerase: promises for future antisense antibiotics development. Infect Disord Drug Targets 11: 175-187.

28. Ji Y, Yin D, Fox B, Holmes DJ, Payne D, et al. (2004) Validation of antibacterial mechanism of action using regulated antisense RNA expression in Staphylococcus aureus. FEMS Microbiol Lett 231: 177-184

29. Borukhov S, Nudler E (2008) RNA polymerase: The vehicle of transcription. Trends Microbiol 16: 126-134.
30. Paget MS, Helmann JD (2003) The sigma70 family of sigma factors. Genome Biol 4: 203.

31. Lane WJ, Darst SA (2010) Molecular evolution of multisubunit RNA polymerases: sequence analysis. J Mol Biol 395: 671-685.

32. Dubos RJ (1939) Studies on a bactericidal agent extracted from a soil bacillus: li. Protective effect of the bactericidal agent against experimental pneumococcus infections in mice. J Exp Med 70: 11-17.

33. Hotchkiss RD, Dubos RJ (1940) Fractionation of the bactericidal agent from cultures of a soil Bacillus. J Biol Chem 132: 791-792.

34. Van Epps HL (2006) René Dubos: unearthing antibiotics. J Exp Med 203: 259

35. Hirsch JG (1956) Phagocytin: a bactericidal substance from polymorphonuclear leucocytes. J Exp Med 103: 589-611.

36. Scott MG, Gold MR, Hancock RE (1999) Interaction of cationic peptides with lipoteichoic acid and gram-positive bacteria. Infect Immun 67: 6445-6453.

37. Brumfitt W, Salton MRJ, Hamilton-Miller JMT (2002) Nisin, alone and combined with peptidoglycan-modulating antibiotics: activity against methicillin-resistant Staphylococcus aureus and vancomycin-resistant Enterococci. J Antimicrob Chemother 50: 731-734.

38. Zhao X, Wu H, Lu H, Li G, Huang Q (2013) LAMP: A Database Linking Antimicrobial Peptides. PLoS One 8: e66557.

39. Conlon JM, Sonnevend A, Davidson C, Smith DD, Nielsen PF (2004) The ascaphins: A family of antimicrobial peptides from the skin secretions of the most primitive extant frog, Ascaphus truei. Biochem Biophys Res Commun 320: $170-175$.

40. Radek K, Gallo R (2007) Antimicrobial peptides: Natural effectors of the innate immune system. Semin Immunopathol 29: 27-43.

41. Peters BM, Jabra-Rizk MA, O'May GA, Costerton JW, Shirtliff ME (2012) Polymicrobial interactions: impact on pathogenesis and human disease. Clin Microbiol Rev 25: 193-213.

42. Leippe M (1999) Antimicrobial and cytolytic polypeptides of amoeboid protozoa-effector molecules of primitive phagocytes. Dev Comp Immunol 23: 267-279.

43. Zasloff M (2002) Antimicrobial peptides of multicellular organisms. Nature 415 389-395.

44. Schauber J, Gallo RL (2008) Antimicrobial peptides and the skin immune defense system. J Allergy Clin Immunol 122: 261-266.

45. Powers JP, Hancock RE (2003) The relationship between peptide structure and antibacterial activity. Peptides 24: 1681-1691.

46. Huang Y, Huang J, Chen Y (2010) Alpha-helical cationic antimicrobial peptides: Relationships of structure and function. Protein Cell 1: 143-152.

47. Bulet $P$, Stöcklin R, Menin L (2004) Anti-microbial peptides: From invertebrates to vertebrates. Immunol Rev 198: 169-184.

48. Laquerre S, Argnani R, Anderson DB, Zucchini S, Manservigi R, et al. (1998) Heparan sulfate proteoglycan binding by herpes simplex virus type 1 glycoproteins $B$ and $C$, which differ in their contributions to virus attachment penetration, and cell-to-cell spread. J Virol 72: 6119-6130.

49. Andersen JH, Jenssen H, Sandvik K, Gutteberg TJ (2004) Anti-HSV activity of lactoferrin and lactoferricin is dependent on the presence of heparan sulphate at the cell surface. J Med Virol 74: 262-271.

50. Park CB, Kim HS, Kim SC (1998) Mechanism of action of the antimicrobial peptide buforin II: Buforin II kills microorganisms by penetrating the cell membrane and inhibiting cellular functions. Biochem Biophys Res Commun 244: 253-257.

51. Otvos L Jr, O I, Rogers ME, Consolvo PJ, Condie BA, et al. (2000) Interaction between heat shock proteins and antimicrobial peptides. Biochemistry 39 $14150-14159$

52. Kragol G, Lovas S, Varadi G, Condie BA, Hoffmann R, et al. (2001) The antibacterial peptide pyrrhocoricin inhibits the ATPase actions of DnaK and prevents chaperone-assisted protein folding. Biochemistry 40: 3016-3026.

53. Jiang Z, Vasil AI, Hale JD, Hancock RE, Vasil ML, et al. (2008) Effects of net charge and the number of positively charged residues on the biological activity of amphipathic alpha-helical cationic antimicrobial peptides. Biopolymers 90 369-383. 
Citation: Sharma M, Singh S, Sharma S (2015) New Generation Antibiotics/Antibacterials: Deadly Arsenal for Disposal of Antibiotic Resistant Bacteria. J Microb Biochem Technol 7: 374-379. doi:10.4172/1948-5948.1000241

54. Lee DG, Hahm KS, Shin SY (2004) Structure and fungicidal activity of a synthetic antimicrobial peptide, P18, and its truncated peptides. Biotechnol Lett 26: $337-341$

55. Lee DG, Kim HK, Kim SA, Park Y, Park SC, et al. (2003) Fungicidal effect of indolicidin and its interaction with phospholipid membranes. Biochem Biophys Res Commun 305: 305-310.

56. Zasloff M (1987) Magainins, a class of antimicrobial peptides from Xenopus skin: isolation, characterization of two active forms, and partial cDNA sequence of a precursor. Proc Natl Acad Sci U S A 84: 5449-5453.

57. Park Y, Jang SH, Lee DG, Hahm KS (2004) Antinematodal effect of antimicrobial peptide, PMAP-23, isolated from porcine myeloid against Caenorhabditis elegans. J Pept Sci 10: 304-311.

58. Fan Z, Cao L, He Y, Hu J, Di Z, et al. (2011) Ctriporin, A new antimethicillinresistant Staphylococcus aureus peptide from the venom of the scorpion Chaerilus tricostatus. Antimicrob Agents Chemother 55: 5220-5229.

59. LaSarre B, Federle MJ (2013) Exploiting quorum sensing to confuse bacterial pathogens. Microbiol Mol Biol Rev 77: 73-111.

60. Cotar AL (2013) Quorum sensing inhibitors as anti-pathogenic drugs in the fight against $P$ seudomonas aeruginosa infections. Clin Microbial 2.

61. Smith RS, Iglewski BH (2003) P. aeruginosa quorum-sensing systems and virulence. Curr Opin Microbiol 6: 56-60.

62. O'Loughlin CT, Miller LC, Siryaporn A, Drescher K, Semmelhack MF, et al. (2013) A quorum-sensing inhibitor blocks Pseudomonas aeruginosa virulence and biofilm formation. Proc Natl Acad Sci U S A 110: 17981-17986.

63. Norizan SN, Yin WF, Chan KG (2013) Caffeine as a potential quorum sensing inhibitor. Sensors (Basel) 13: 5117-5129.

64. Therien AG, Joann L, Huber B, Kenneth E, Wilson B, et al. (2012) Broadening the spectrum of lactam antibiotics through inhibition of signal peptidase type I. Antimicrob Agents and Chemother 56: 4662-4670

65. Paetzel M, Karla A, Strynadka NC, Dalbey RE (2002) Signal peptidases. Chem Rev 102: 4549-4580.

66. Lemire JA, Harrison JJ, Turner RJ (2013) Antimicrobial activity of metals: Mechanisms, molecular targets and applications. Nat Rev Microbiol 11: 371-384.

67. Azam A, Ahmed AS, Oves M, Khan MS, Memic A (2012) Size-dependen antimicrobial properties of $\mathrm{CuO}$ nanoparticles against Gram-positive and -negative bacterial strains. Int J Nanomedicine 7: 3527-3535.

68. Mahapatra O, Bhagat M, Gopalakrishnan C, Arunachalam KD (2008) Ultrafine dispersed $\mathrm{CuO}$ nanoparticles and their antibacterial activity. J Exp Nanosci 3: 185-193.

69. Tran N, Mir A, Mallik D, Sinha A, Nayar S, et al. (2010) Bactericidal effect of iron oxide nanoparticles on Staphylococcus aureus. Int J Nanomedicine 5: 277-283.

70. Matsumura Y, Yoshikata K, Kunisaki S, Tsuchido T (2003) Mode of bactericidal action of silver zeolite and its comparison with that of silver nitrate. Appl Environ Microbiol 69: 4278-4281.

71. Gupta A, Maynes M, Silver S (1998) Effects of halides on plasmid-mediated silver resistance in Escherichia coli. Appl Environ Microbiol 64: 5042-5045.

72. Singh M, Singh S, Prasad S, Gambhir IS (2008) Nanotechnology in medicine and antibacterial effect of silver nanoparticles. Dig J Nanomater Bios 3: 115-122.

73. Gunawan C, Teoh WY, Marquis CP, Amal R (2011) Cytotoxic origin of copper(II) oxide nanoparticles: comparative studies with micron-sized particles, leachate, and metal salts. ACS Nano 5: 7214-7225.

74. Chatterjee AK, Chakraborty R, Basu T (2014) Mechanism of antibacterial activity of copper nanoparticles. Nanotechnology 25: 135101.

75. Jones N, Ray B, Ranjit KT, Manna AC (2008) Antibacterial activity of ZnO nanoparticle suspensions on a broad spectrum of microorganisms. FEMS Microbiol Lett 279: 71-76.

76. Yoon KY, Hoon Byeon J, Park JH, Hwang J (2007) Susceptibility constants of Escherichia coli and Bacillus subtilis to silver and copper nanoparticles. Sci Total Environ 373: 572-575.

77. Ruparelia JP, Chatterjee AK, Duttagupta SP, Mukherji S (2008) Strain specificity in antimicrobial activity of silver and copper nanoparticles. Acta Biomater 4: 707-716.

78. Heinlaan M, Ivask A, Blinova I, Dubourguier HC, Kahru A (2008) Toxicity of nanosized and bulk $\mathrm{ZnO}, \mathrm{CuO}$ and $\mathrm{TiO} 2$ to bacteria Vibrio fischeri and crustaceans Daphnia magna and Thamnocephalus platyurus. Chemosphere 71: $1308-1316$.

79. Studer AM, Limbach LK, Van Duc L, Krumeich F Athanassiou EK et al (2010) Nanoparticle cytotoxicity depends on intracellular solubility: comparison of stabilized copper metal and degradable copper oxide nanoparticles. Toxicology Lett 197: 169-174.

80. Cronholm P, Midander K, Karlsson HL, Elinn K, Wallinder IO et al (2011) Effect of sonication and serum proteins on copper release from copper nanoparticles and the toxicity towards lung epithelial cells. Nanotoxicology 5: 269-281.

81. Wang J, Sun P, Bao Y, Dou B, Song D, et al. (2012) Vitamin E renders protection to PC12 cells against oxidative damage and apoptosis induced by single-walled carbon nanotubes. Toxicol In Vitro 26: 32-41.

82. Drago L, Vassena C, Fenu S, De Vecchi E, Signori V, et al. (2014) In vitro antibiofilm activity of bioactive glass S53P4. Future Microbiol 9: 593-601.

83. Bortolin M, De Vecchi E, Romanò CL, Toscano M, Mattina R, et al. (2015) Antibiofilm agents against MDR bacterial strains: is bioactive glass BAG-S53P4 also effective? J Antimicrob Chemother 